\title{
Technical and tactical analysis of women's volleyball
}

\author{
Virpi Inkinen ${ }^{1,3}$, Mikko Häyrinen ${ }^{2}$, Vesa Linnamo ${ }^{1}$ \\ ${ }^{1}$ Department of Biology of Physical Activity, University of Jyväskylä, Finland, ${ }^{2}$ KIHU - Research Institute for Olympic \\ Sports, Jyväskylä, Finland, ${ }^{3}$ LIKES Research Center for Sport and Health Sciences, Jyväskylä, Finland
}

\section{Summary}

Introduction: The study aim was to construct a technical and tactical analysis of women's volleyball based on notational analysis in top-level and junior women's European volleyball matches, to compare these two levels, and to clarify the differences between the winners and losers of a set.

Material and Methods: Four matches from the 2010 FIVB Women's Volleyball World Championships and 2010 CEV Junior Women's European Championship 2010 were analyzed using Data Volley software. The number and performance level of different skills were recorded in total and were grouped according to the role of the players. Methods of scoring and attacking zones were also analyzed.

Results: There were only slight differences between the two levels in terms of success in different skills. When the skill executions were compared between the winning and losing teams of a set within the levels, less successful skill executions and more errors in different skills were found for the losing teams.

Conclusions: The results seem to indicate that there are only minor differences between adult and junior women's volleyball at the highest level. Attacking seems to be the most important skill concerning winning in both levels. The efficiency of attacking seems to depend upon the quality and versatility of the setting and also from the physical abilities of the players.

\section{Keywords: Female - Volleyball - Notational analysis}

\section{Introduction}

Performance analysis is a way to understand the factors explaining success in elite-level sports. It gives coaches knowledge of the sport so they can think of ways to develop playing and training $[8,9]$. Performance analysis has been recently utilized in different levels of volleyball in many studies $[1,2,4,5,10,12,14$, 15, 19, 20, 21].

A volleyball match consists of different volleyballspecific technical skill executions, which are serve, reception, set, attack, block, and defense. There is technical variability in the execution of these basic skills (eg, serves can be divided into jump serves, jump float serves, and float serves). The success of these skill executions is dependent on the tactical skills and physical capabilities of the players [10, 20].

Previous studies have analyzed player and team performance in several top-level women's and men's volleyball tournaments. The efficiency of different skills has been observed in relation to winning a match or a set. In women's volleyball, serve and attack have a major role in winning the set. Also, it has been noted that digging is important in women's volleyball. Blocking is also relevant to a team's success and likelihood of winning $[3,11,13,14,16-18,21]$.

Several studies have found that there are differences between women's and men's volleyball matches. The rallies in men's matches have been shorter than in women's matches, and women have executed more digs than men. Men served more jump serves, but women used more jump float and float serves. On the other hand, men executed reception by overhand pass more often than women. Men's receptions were also more efficient than women's. Men's attacks were also more powerful and efficient than women's. Men's attacking tempos have been quicker than women's, and women also tend to use a different attacking technique than men in quick attacks $[3,5,16]$. According to Mesquita and Cesar [13], the opposite player's attacks from zone 1 made by men were more efficient than those made by women in the 2004 Olympics. Women's attacks from zone 1 were more likely a back-up solution 
rather than an actual tactical option. However, they suggested that in the future the opposite player's attack from zone 1 may become a tactical solution in women's volleyball as it is in men's [13].

However, there are no studies that compare different levels of women's volleyball. Physical characteristics and skill level of elite junior female players may not be as well developed as in adult elite players. Therefore, it was of interest to examine whether any differences could be found in the technical and tactical aspects between the two age groups.

This study analyzed women's volleyball matches from the FIVB Women's Volleyball World Championships (WC) and the CEV Junior European Championship tournament (JEC). The purpose was to compare these two levels and clarify the differences between the winning and losing sets in women's top-level European volleyball matches.

\section{Methods}

In this study, four matches from the WC and four matches from the JEC were analyzed. These matches were selected from the final phases of each tournament, and the competing teams were judged to be of equal ability. All teams played the same game system as that presented by Durkovic et al [6]. and Zadraznik et al [22]. Under these circumstances, comparisons between technical and tactical variables are meaningful.

Data Volley 3.4.2 game analysis software (Data Project, Italy) was used to determine the number and performance level of different skills in total, as well as by the role of the players. The criteria of the performance level evaluation were based on Eom and Schutz [7] and Häyrinen et al. [10]. The criteria are presented in table 1 . The percentages of success and error in different skills were calculated as shown in table 1 . The number of blocking points and the number of errors were calculated as averages of sets.

The percentage of scoring in own and the opponent's serving turn was analyzed. Ways of scoring (sideout attack, counterattack, serve, block, opponent's unforced errors, and opponent's forced errors) were also determined in every set.

The serving type was defined as jump serve, jump float serve, or overhead float serve. The number of attacks from the different attacking zones was also analyzed in both side-out attacks and counterattacks. The attacking zones were determined after good and weak reception. Success in attacks was determined by the attacking zones in both side-out attacks and counterattacks. The number of different skill executions was calculated per set and by player role.
The statistical analysis of the matches was made by PASW Statistics 18 and IBM SPSS Statistics 20 (IBM SPSS, USA) and Microsoft Office Excel 2003 and 2010 software (Microsoft Corporation, USA). The fifth sets were not included in the analysis because the results were deviant from the other sets. Statistical comparison between the two levels and comparisons between the winning and losing teams were made by nonparametric Mann-Whitney U test. The level of statistical significance was determined as $\alpha=0.05$. All comparisons were made by the number of skills, not by percentage of the distribution of sets.

All the matches were analyzed and recorded by one observer and revised by an experienced notational analysis researcher. One match was recorded twice in notational analysis. Both skill evaluations and players' performance analogy were excellent (Cohen's $\kappa=0.889-1.0)$. The number of attacks in one rally was noted equally (Cohen's $\kappa=0.96)$.

\section{Results}

\section{Point Scoring}

The percentage of scoring points in own serving turn was $41.8 \%$ in WC and $43.1 \%$ in JEC (ns). However, when winning a set, teams scored significantly more points in their own serving turns than when losing a set: $46.6 \%$ and $35.9 \%$ in $\mathrm{WC}$ and $47.9 \%$ and $37.0 \%$ in JEC ( $p<0.01$ both).

The scoring ways in total and separately in the winning and losing sets are presented in table 2. Most of the points were gained by side-out attacks and counterattacks in both WC and JEC. In WC, the winners of the set received more points from opponent's forced errors than the losers did $(p<0.05)$. In JEC, teams scored more points with serves than in WC $(p<0.05)$. Also, the winner of the set scored more points with serves in JEC than in WC $(p<0.05)$.

\section{The Number of Skills and Success in Different Skills}

A team executed on average 177.9 different skills in one set in JEC and 182.6 in WC. The number of skills per set subdivided by player role is presented in table 3. The main difference between the levels was that the liberos executed fewer skill executions and especially receptions in WC than in JEC $(p<0.01)$. Some differences were also found between the two levels in the number of the skills executed by outside and middle players starting from different positions.

The most used serve technique was the jump float serve $(70.3 \%$ of serves in WC and $89.2 \%$ in JEC $89.2 \%$; $p<0.05$ ), while $19.2 \%$ of serves were overhand float serves in WC and $6.9 \%$ in JEC $(p<0.001)$ and $10.5 \%$ 
Table 1. Criteria of the Performance Level of Technical Skill Executions and Means of Calculating Percentages of Success $(+\%)$ and Errors $(-\%)$
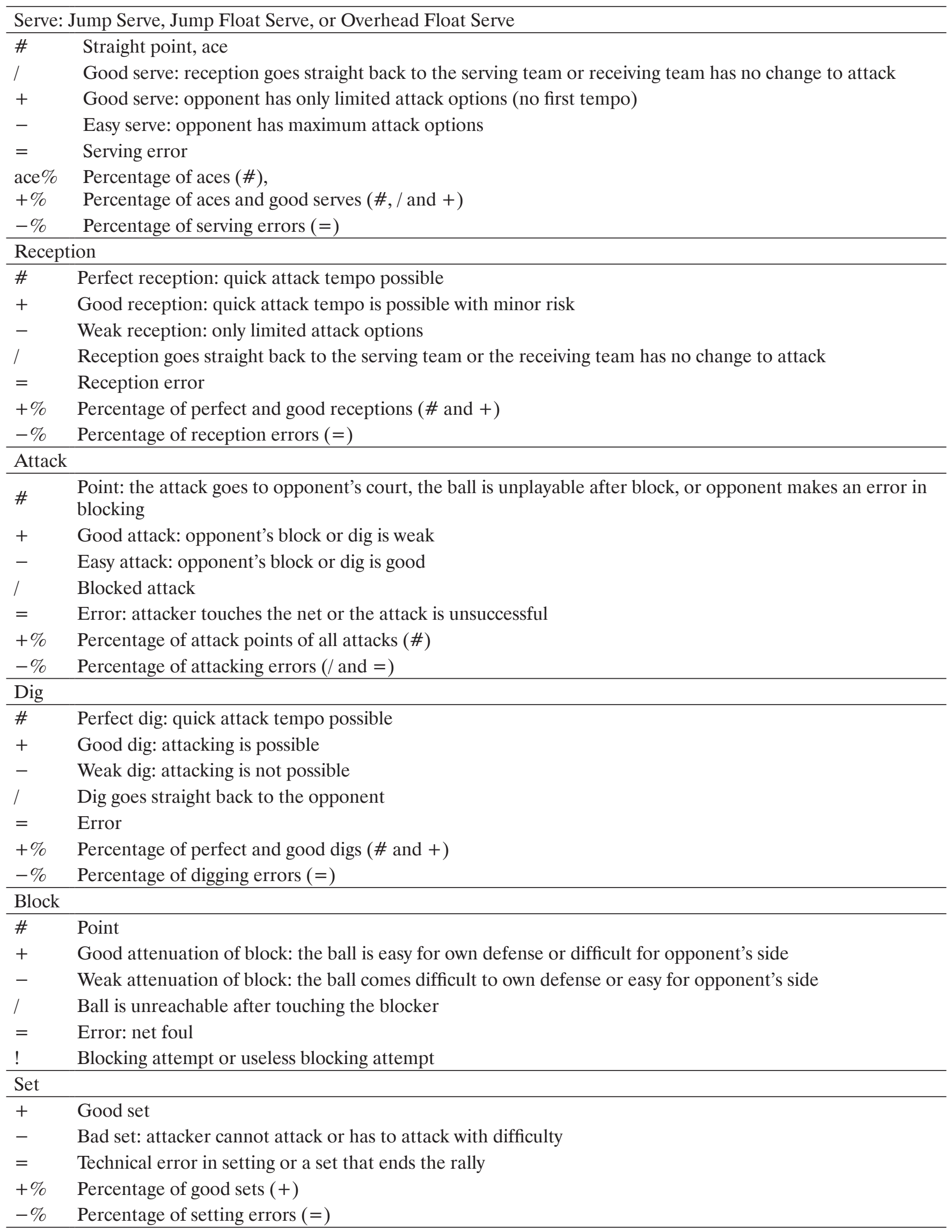
Table 2. Ways of scoring

\begin{tabular}{cccccccc}
\hline & & $\begin{array}{c}\text { Side-out } \\
\text { attack }\end{array}$ & $\begin{array}{c}\text { Counter- } \\
\text { attack }\end{array}$ & Serve & Block & $\begin{array}{c}\text { Opponent's } \\
\text { unforced error }\end{array}$ & $\begin{array}{c}\text { Opponent's } \\
\text { forced error }\end{array}$ \\
\hline WC & losing set & $32.0 \%$ & $30,2 \%$ & $6,0 \%$ & $9,3 \%$ & $14,2 \%$ & $8,2 \%^{\mathrm{c}}$ \\
& winning set & $29.2 \%$ & $29,5 \%$ & $6,0 \% \%^{\mathrm{a}}$ & $10,9 \%$ & $13,5 \%$ & $10,9 \%^{\mathrm{c}}$ \\
& total & $30.5 \%$ & $29,8 \%$ & $6,0 \% \%^{\mathrm{b}}$ & $10,2 \%$ & $13,8 \%$ & $9,7 \%$ \\
JEC & losing set & $29.0 \%$ & $24,3 \%$ & $8,0 \%$ & $11,3 \%$ & $16,7 \%$ & $10,7 \%$ \\
& winning set & $25.9 \%$ & $25,9 \%$ & $10,3 \%^{\mathrm{a}}$ & $13,2 \%$ & $16,1 \%$ & $8,5 \%$ \\
& total & $27.3 \%$ & $25,2 \%$ & $9,3 \% \%^{\mathrm{b}}$ & $12,4 \%$ & $16,4 \%$ & $9,4 \%$ \\
\hline
\end{tabular}

a-b: statistically significant differences between levels $(p<0.05)$; : statistically significant difference between winning and losing sets $(p<0.05)$.

Table 3. The number of skills per set subdivided by player role (the number after the player's role denotes the position of the player on the court when the setter is in rotation one)

\begin{tabular}{|c|c|c|c|c|c|c|c|c|c|}
\hline & & Setter & $\begin{array}{l}\text { Outside } \\
\text { player } 2\end{array}$ & $\begin{array}{l}\text { Middle } \\
\text { player } 3\end{array}$ & $\begin{array}{c}\text { Opposite } \\
\text { player }\end{array}$ & $\begin{array}{l}\text { Outside } \\
\text { player } 5\end{array}$ & $\begin{array}{l}\text { Middle } \\
\text { player } 6\end{array}$ & Libero & Sum \\
\hline \multirow[t]{9}{*}{ WC } & Serve & 4.3 & 4.2 & 3.5 & 3.7 & 3.3 & 3.5 & - & 22.5 \\
\hline & Attack & 0.6 & 6.3 & 2.9 & 11.0 & 6.8 & $4.0^{\mathrm{f}}$ & - & 31.6 \\
\hline & Reception & 0.1 & 7.5 & 0.2 & 0.1 & $8.7^{\mathrm{e}}$ & 0.1 & $3.6^{\mathrm{g}}$ & 20.3 \\
\hline & $\begin{array}{l}\text { Block with ball } \\
\text { contact }\end{array}$ & 1.5 & 1.2 & 3.2 & 2.0 & 1.5 & 2.7 & - & 12.3 \\
\hline & $\begin{array}{c}\text { Block without ball } \\
\text { contact }\end{array}$ & 5.8 & 4.5 & 11.9 & 6.4 & 5.5 & 9.7 & - & 43.9 \\
\hline & Dig & 3.0 & 2.8 & 0.8 & 2.5 & 3.7 & 1.2 & 5.0 & 19.0 \\
\hline & Set & 26.2 & 0.4 & 0.8 & 0.6 & 0.5 & 0.8 & 1.4 & 30.8 \\
\hline & Free ball & 0.4 & 0.6 & 0.1 & 0.2 & 0.4 & 0.2 & 0.3 & 2.2 \\
\hline & Total skills & 41.9 & $27.5^{\mathrm{a}}$ & $23.5^{\mathrm{b}}$ & 26.5 & $30.4^{\mathrm{c}}$ & 22.2 & $10.3^{\mathrm{d}}$ & 182.6 \\
\hline \multirow[t]{9}{*}{ JEC } & Serve & 3.8 & 4.3 & 3.4 & 3.2 & 4.1 & 3.7 & - & 22.6 \\
\hline & Attack & 1.0 & 7.3 & 2.0 & 9.7 & 7.1 & $2.5^{\mathrm{f}}$ & - & 29.8 \\
\hline & Reception & 0.1 & 8.7 & 0.1 & 0.5 & $4.5^{\mathrm{e}}$ & 0.1 & $6.2^{\mathrm{g}}$ & 20.2 \\
\hline & $\begin{array}{l}\text { Block with ball } \\
\text { contact }\end{array}$ & 1.6 & 1.6 & 2.8 & 1.7 & 1.3 & 3.3 & - & 12.3 \\
\hline & $\begin{array}{l}\text { Block without ball } \\
\text { contact }\end{array}$ & 5.9 & 4.4 & 10.1 & 6.4 & 4.5 & 10.3 & - & 41.5 \\
\hline & Dig & 2.8 & 3.2 & 1.2 & 2.3 & 2.8 & 1.3 & 6.0 & 19.6 \\
\hline & Set & 24.3 & 0.5 & 0.7 & 0.4 & 1.1 & 1.1 & 1.1 & 29.3 \\
\hline & Free ball & 0.4 & 0.5 & 0.2 & 0.7 & 0.4 & 0.1 & 0.3 & 2.6 \\
\hline & Total skills & 39.9 & $30.5^{\mathrm{a}}$ & $20.4^{\mathrm{b}}$ & 25.0 & $25.9^{c}$ & 22.4 & $13.8^{\mathrm{d}}$ & 177.9 \\
\hline
\end{tabular}

a-g: statistically significant differences between levels (a-c: $p<0.05$, d and f-g: $p<0.01$ and e: $p<0.001$ ).

of serves were jump serves in $\mathrm{WC}$ and $3.8 \%$ in JEC $(p<0.05)$.

The success and error percentages in different skills and the number of kill and error blocks are presented in table 4. Generally, the winning teams made more kill and fewer error blocks than the losing teams, though the differences were not significant. There were significant differences in aces and reception errors between the winning and losing teams in JEC $(p<0.05$ both). There were significantly more successful and 
Table 4. Success $(+\%)$ and error $(-\%)$ percentages in different skills

\begin{tabular}{|c|c|c|c|c|c|c|c|c|c|c|c|c|}
\hline & & \multicolumn{3}{|c|}{ Serve } & \multicolumn{2}{|c|}{ Reception } & \multicolumn{2}{|c|}{ Block average/set } & \multicolumn{2}{|c|}{ Dig } & \multicolumn{2}{|c|}{ Set } \\
\hline & & ace $\%$ & $+\%$ & $-\%$ & $+\%$ & $-\%$ & + & - & $+\%$ & $-\%$ & $+\%$ & $-\%$ \\
\hline \multirow[t]{3}{*}{ WC } & losing set & 5.9 & 38.9 & 10.1 & 56.1 & 6.8 & 1.9 & 5.1 & $69.7^{\mathrm{a}}$ & 17.9 & 94.9 & 0.7 \\
\hline & winning set & 6.1 & 39.8 & 9.4 & 56.8 & 6.6 & 2.7 & 4.3 & $72.3^{\mathrm{a}}$ & 18.1 & 95.1 & 0.7 \\
\hline & total & $6.0^{*}$ & $39.4^{* *}$ & 9.7 & $56.4^{* *}$ & $6.7^{*}$ & 2.3 & 4.7 & 71.1 & 18.0 & $95.0^{*}$ & $0.7^{*}$ \\
\hline \multirow[t]{5}{*}{ JEC } & losing set & $7.8^{\mathrm{a}}$ & 47.4 & 12.0 & 45.7 & $11.6^{\mathrm{b}}$ & 2.3 & 4.6 & 64.2 & 21.2 & 89.6 & 2.2 \\
\hline & winning set & $10.5^{\mathrm{a}}$ & 49.2 & 9.5 & 46.1 & $8.9^{\mathrm{b}}$ & 3.3 & 4.0 & 70.6 & 17.1 & 90.9 & 1.4 \\
\hline & total & $9.3^{*}$ & $48.4^{* *}$ & 10.6 & $45.9^{* *}$ & $10.4^{*}$ & 2.8 & 4.3 & 67.5 & 19.1 & $90.2^{*}$ & $1.8^{*}$ \\
\hline & & \multicolumn{2}{|c|}{ All attacks } & \multicolumn{2}{|c|}{ Side-out attack } & \multicolumn{2}{|c|}{ Counter attack } & & & & & \\
\hline & & $+\%$ & $-\%$ & $+\%$ & $-\%$ & $+\%$ & $-\%$ & & & & & \\
\hline \multirow[t]{3}{*}{ WC } & losing set & $39.4^{\mathrm{c}}$ & $20.5^{\mathrm{d}}$ & 36.0 & $25.6^{\mathrm{e}}$ & 43.8 & 13.9 & & & & & \\
\hline & winning set & $46.6^{\mathrm{c}}$ & $12.3^{\mathrm{d}}$ & 48.8 & $11.5^{\mathrm{e}}$ & 44.6 & 13.0 & & & & & \\
\hline & total & $43.0^{*}$ & 16.4 & 42.4 & 18.6 & 44.2 & 13.5 & & & & & \\
\hline \multirow[t]{3}{*}{ JEC } & losing set & 35.6 & 21.2 & 34.7 & $21.9^{\mathrm{f}}$ & $36.9^{\mathrm{i}}$ & 20.2 & & & & & \\
\hline & winning set & 44.0 & 16.2 & 46.4 & $14.7^{\mathrm{f}}$ & $41.9^{\mathrm{i}}$ & 17.5 & & & & & \\
\hline & total & $39.8^{*}$ & 18.7 & 40.6 & 18.3 & 39.4 & 18.9 & & & & & \\
\hline
\end{tabular}

a-c, f: statistically significant differences between winning and losing sets $(p<0.05)$; d: statistically significant differences between winning and losing sets $(p<0.01)$; e: statistically significant differences between winning and losing sets $(p<0.001) ;{ }^{*},{ }^{* *}$ : statistically significant difference between levels $\left({ }^{*} p<0.05,{ }^{* *} p<0.01\right)$. The analysis has been made only in total not between winning and losing sets.

fewer error receptions in WC than in $\operatorname{JEC}(p<0.01$ and $p<0.05)$, while there were more aces and successful serves in JEC than in WC $(p<0.05$ and $p<0.01)$. Also, there were more successful sets and fewer errors in WC than in JEC ( $p<0.05$ both).

The success and error percentages of the winning and losing teams in all attacks and separately in sideout attacks and counterattacks are presented also in table 4 . The success percentage of the attacks was higher in WC than in JEC $(p<0.05)$. The winning teams had a higher success percentage $(p<0.05)$ and a lower error percentage $(p<0.01)$ in all attacks than the losing teams in WC. The winning teams had a lower error percentage in the side-out attacks than the losing teams within both levels ( $p<0.05$ both).

In WC, the most successful $(+45.0 \%)$ attacking zone in the side-out attacks was backcourt attacks (zones 1 and 6 together) followed closely by zone 3 attacks $(+44.5 \%)$. In JEC, zone 3 was clearly the most successful area $(+46.0 \%)$. In both levels, the error percentage was lowest in zone 3 (WC 15.8\% and JEC $16.1 \%)$. There were no significant differences either within or between the levels.

When the winners of the sets were compared to the losers, it was found that the success percentages in the side-out attacks from different attacking zones were better for the winners than for the losers, except attacks from zone 3 in JEC. The only significant difference was found in WC for zone $2(56.4 \%$ vs. $24.4 \%$; $p<0.01)$. The error percentages were smaller for the winners than for the losers, except attacks from zone 3 in JEC. The differences were significant in WC for zone $3(22.0 \%$ vs. $7.8 \% ; p<0.01)$ and for zone $2(31.7 \%$ vs. $5.1 \% ; p<0.05)$ and in JEC for zone 2 (27.6\% vs. $17.9 \%$; $p<0.05$ ). Between the two levels, significant differences were found in terms of success in zone 3 for the winning teams (WC 51.6\% vs. JEC $43.6 \% ; p<0.05)$ and errors in zone 3 for the losing teams (WC $22.0 \%$ vs. JEC $14.6 \%$; $p<0.05$ ).

\section{Distribution of the Sets into the Different Attacking Zones}

The distribution of sets into the different attacking zones is presented in figure 1a separately for side-out attacks and counterattacks. In total, there were more sets into zone 3 in WC than in JEC $(p<0.05)$. There were more sets to zone 3 in side-out attacks than in counterattacks in WC and in JEC $(p<0.001$ and $p<0.05)$. There were also more sets to zone 4 in sideout attacks than in counterattacks in JEC $(p<0.05)$. In side-out attacks, there were more sets to zone 3 in WC than in JEC $(p<0.001)$, whereas there were more sets to zone 4 in JEC than in WC $(p<0.01)$.

The distribution of sets into the different attacking zones in side-out attacks after good and weak 


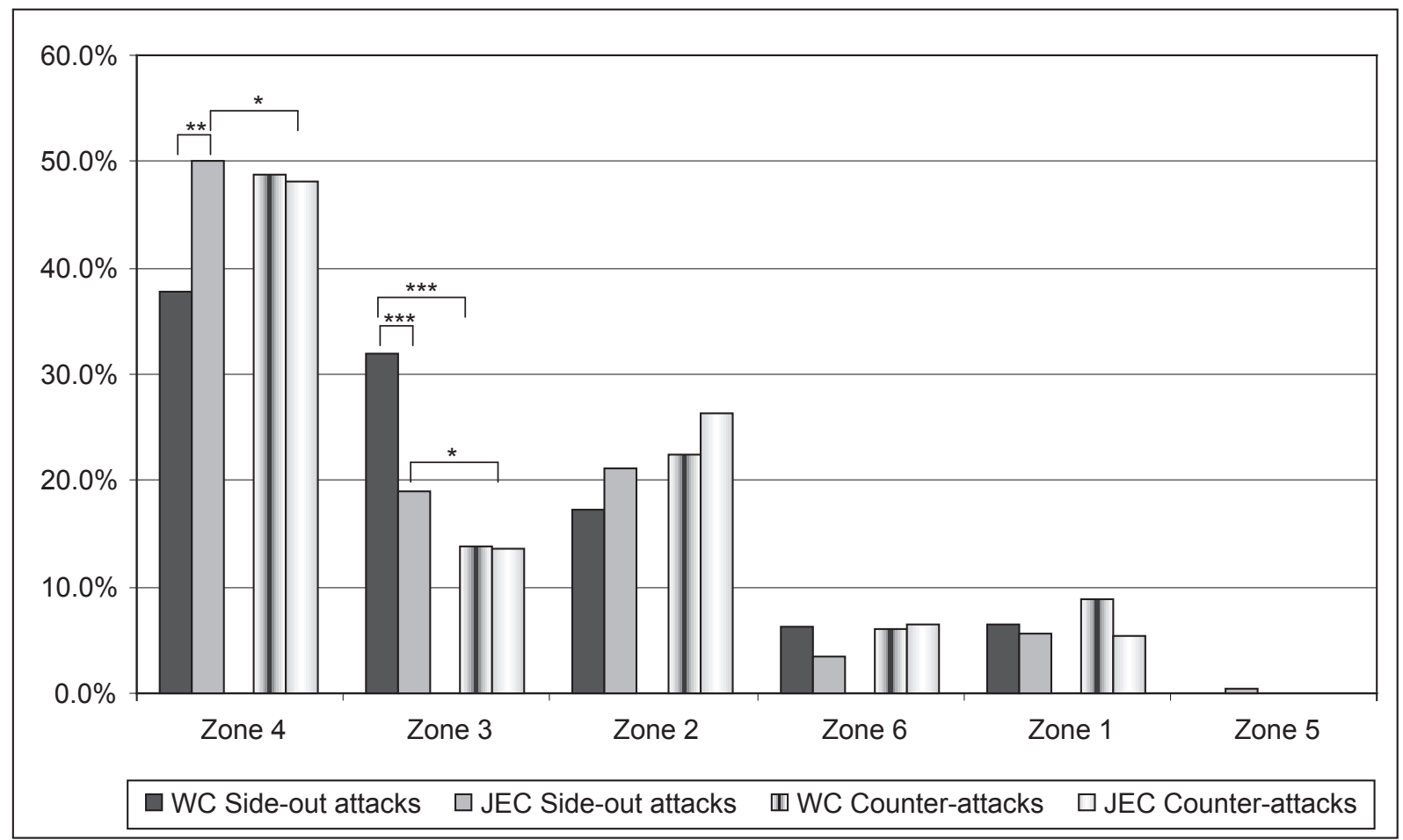

Figure 1a. Set distribution into different attacking zones in side-out and counter-attack situations

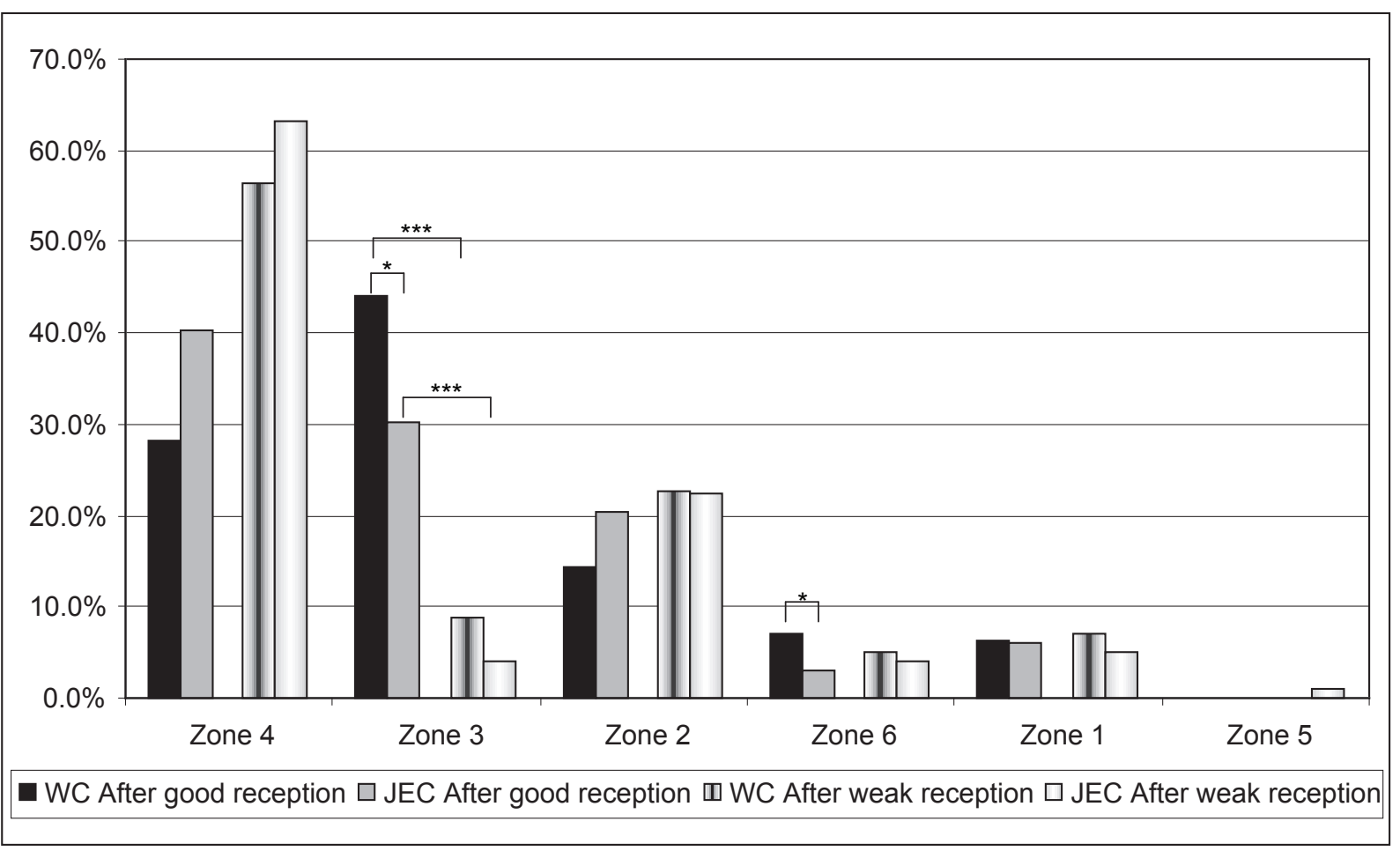

Figure 1b. Set distribution into different attacking zones in side-out situations after good and weak reception

Figure 1. Set distribution into different attacking zones in side-out and counter-attack situations $\left({ }^{*} p<0.05,{ }^{* *} p<0.01\right.$, $* * * p<0.001)$

receptions is also presented in figure $1 \mathrm{~b}$. There were more sets to zone 3 and to zone 6 after good reception in WC than in JEC $(p<0.001$ and $p<0.05)$. There were also more sets to zone 3 after good reception than after weak reception in both WC and $\operatorname{JEC}(p<0.001$ both). 


\section{Discussion}

There were only minor differences between the two levels of high-level women's volleyball. The main differences were found in the success and error rates in different skills and also in set distribution. On the other hand, when the winners and the losers of a set were compared, it was found that the winners were more efficient in attacking in both levels.

More points were scored by serving and blocking at the junior level and by attacking at the adult level. The juniors made more aces and had a higher success percentage in serving than the adult women. On the other hand, adults had higher success in receiving and in attacking. The reason for these differences might be the fact that the juniors have less developed physical and technical abilities and that efficient attacking and receiving require highly developed physical qualities. Efficient jump float serving, on the other hand, is not so demanding of the physical abilities. The differences in the set distribution and set quality might originate from the skill level of the setters. Normally, the junior setters are not as skillful as the adult setters.

At the adult level, some differences were found in the types of serving compared to previous studies. According to Palao et al. [16], based on an analysis made in the 2005 Mediterranean Games, women served overhead float serves most often (48\%), followed by jump serves (37\%) and jump float serves (15\%). In this study, jump float serve was the dominant serve technique in both levels (WC $70 \%$ and JEC 89\%). The success and error percentages in different skill executions did not differ considerably between this study and the study of Palao et al. [16].

Generally, the success percentages in different skills were higher for the winning teams than for the losing teams. Conversely, error percentages were smaller for the winning teams than for the losing teams. There were also more blocks and fewer blocking errors for the winning teams than for the losing teams. At the 2000 Olympics, teams at a higher level were more successful than teams at a lower level in attack, reception, block, and dig [17].

The winning teams of a set were better especially in attacking (higher success percentages and lower error percentages), so it seems that attacking is also an important skill concerning winning in elite-level women's volleyball as well as in men's volleyball $[7,10,17]$. The difference is remarkable, especially in side-out attacking even if the differences in the success percentage (WC $49 \%$ vs. $36 \%$ and JEC $46 \%$ vs. $35 \%$ ) are not statistically significant. The reason for this might be the difference in the exact level of setting, which was not evaluated in this study. Previously, it had been noted that after a good set, $80 \%$ of attacks ended successfully, whereas after a weak set, half of the attacks ended with an error [3]. On the other hand, Afonso et al. [2] reported that the setter's jump set increased the attack tempo, thus complicating the opponent's blocking attempt. Palao et al. [18] also noted that a higher attacking tempo increased the efficiency of both side-out attacks and counterattacks. Also, the level of digging has an effect on the success of the attacking, and Miskin et al. [14] suggested that digging is an important skill in women's volleyball.

The set distribution to different attacking zones was more versatile in adults than in juniors, especially in side-out phase. Zone 3 (quick) and back row attacks were used more by adults. This makes blocking and digging more difficult and might explain the higher success in attacking in the adult level $[2,18]$. When the results of the adult level are compared to 2000 Olympic Games, it can be seen that the use of zone 3 and back court attacks has increased and the use of zone 4 decreased [18]. The results of this study support the study of Mesquita and Cesar [13], who suggested that zone 1 attacks are likely to become an efficient tactical solution rather than merely a back-up solution, especially in WC.

The limitations of this study are the rather low number of matches. Analyzing more matches might give more reliable results for interpretation of the results. Also, the use of only one analyst may have an effect on the results, but the analyst was educated by two experienced analysts and the reliability of the analysis was high.

To conclude, the results of this study seem to indicate that there are only minor differences between adult and junior women's volleyball at the highest levels. Attacking seems to be the most important skill concerning winning in both levels. The efficiency of attacking seems to depend upon the quality and versatility of the setting and also upon the physical abilities of the players.

\section{References}

1. Afonso J., F. Esteves, R. Araújo, L. Thomas, I. Mesquita (2012) Tactical determinants of setting zone in elite men's volleyball. J. Sports Sci. Med., 11: 64-70.

2. Afonso J., I. Mesquita, R. Marcelino, J. da Silva (2010) Analysis of the setter's tactical action in high-performance women's volleyball. Kinesiology, 42: 82-89.

3. Bergeles N., K. Barzouka, N. Elissavet (2009) Performance of male and female setters and attackers on Olympic-level volleyball teams. Int. J. Perform. Analysis Sport, 9: 141-148. 
4. Bozhkova A. (2013) Playing efficiency of the best volleyball players in the world. Research in Kinesiology, 41: 92-95.

5. Costa G., J. Afonso, E. Brant, I. Mesquita (2012) Differences in game patterns between male and female youth volleyball. Kinesiology, 4: 60-66.

6. Durkovic T., N. Marelic, T. Resetar (2008) Influence of the position of players in rotation on differences between winning and losing teams in volleyball. Int. J. Perform. Analysis Sport, 8: 8-15.

7. Eom H., R. Schutz (1992) Statistical analyses of volleyball performance. Res. Q. Exerc. Sport, 63: 11-18.

8. Garganta J. (2012) Trends of tactical performance analysis in team sport bridging the gap between research training and competition. Rev. Port. Cien.Desp., 9: 81-89.

9. Hughes M., R. Bartlett (2002) The use of performance indicators in performance analysis. J. Sports Sci., 20: 739-754.

10. Häyrinen M., H. Lehto, T. Mikkola, P. Honkanen, A. Paananen, P. Lahtinen, M. Blomqvist (2010) Miesten lentopallon lajianalyysi kolmella eri tasolla (Technical and tactical game analysis of men's elite volleyball in three different levels). KIHUn julkaisusarja, nro 16 (The publication series of KIHU, no 16). Jyväskylä: KI$\mathrm{HU}$ - Research Institute for Olympic Sports. Retrieved from KIHU's website: http://www.kihu.fi/tuotostiedostot/ julkinen/2010_hay_miesten_le_sel66_68799.pdf.

11. Lobietti R., R. Di Michele, F. Mermi (2006) Relationships between performance parameters and final ranking in professional volleyball. In Proceedings of WCPAS 2006 Szombathely 24-28 August 2006, World Congress of the Society of Performance Analysis in Sport.

12. Marcelino R., J. Sampaio, I. Mesquita. (2012) Attack and serve performances according to the match period and quality of opposition in elite volleyball matches. J. Strength Cond. Res., 26: 3385-3391.

13. Mesquita I., B. Cesar (2007) Characterisation of the opposite player's attack from the opposition block characteristics. An applied study in the Athens Olympic games in female volleyball teams. Int. J. Perform. Analysis Sport, 7: 13-27.
14. Miskin M., G. Fellingham, L. Florence (2010) Skill importance in women's volleyball. JQAS, 6, Article 5. DOI: 10.2202/1559-0410.1234.

15. Palao J., I. Ahrabi-Fard (2011) Side-out success in relation to setter's position on court in women's college volleyball. IJASS, 23: 155-167.

16. Palao J., P. Manzanares, E. Ortega (2009) Techniques used and efficacy of volleyball skills in relation to gender. Int. J. Perform. Analysis Sport, 9: 281-293.

17. Palao J., J. Santos, A. Urena (2004) Effect of team level on skill performance in volleyball. Int. J. Perform. Analysis Sport, 4: 50-60.

18. Palao J., J. Santos, A. Urena (2007) Effect of the manner of spike execution on spike performance in volleyball. Int. J. Perform. Analysis Sport, 7:1 26-138.

19. Přidal V. J. Hančák, J. (2012) Effects of the quality of selected kinds of game skills of an individual on the set outcome in men's top-level volleyball. Acta Facultatis Educationis Physicae Universitatis Comenianae, 52: 49-60.

20. Quiroga M., J. Garcia-Manso, D. Rodriguez-Ruiz, S. Sarmiento, Y. De Saa, M. Moreno (2010) Relation between in-game role and service characteristics in elite women's volleyball. J. Strength Cond. Res., 24: 2316-2321.

21. Rodriguez-Ruiz D., M. Quiroga, J. Miralles, S. Sarmiento, Y. de Saa, J. Garcia-Manso (2011). Study of the technical and tactical variables determining set win or loss in top-level European men's volleyball. JQAS, 7, Article 7. DOI: $10.2202 / 1559-0410.1281$.

22. Zadraznik M., N. Marelic, T. Resetar (2009) Differences in rotations between the winning and losing teams at the youth European volleyball championships for girls. Acta Universitatis Palackianae Olomucensis Gymnica, 39: 33-40.

\section{Received 24.11.2012 \\ Accepted 09.09.2013}

(C) University of Physical Education, Warsaw, Poland 